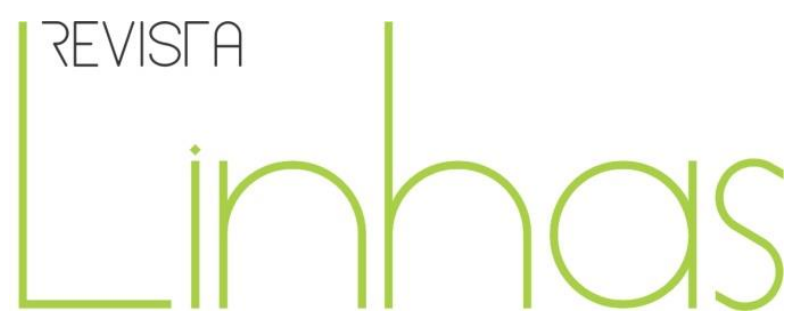

\title{
Manuais pedagógicos e programas de ensino: interpretações da Escola Nova sobre a prática de ensino na formação de professores (1946-1961)
}

\begin{abstract}
Resumo
O presente estudo intenta contribuir para a compreensão do movimento de circulação das ideias da Escola Nova no estado de São Paulo, entre os anos de 1946 e 1961, considerado pela historiografia como período de sedimentação das diretrizes escolanovistas no âmbito normativo de leis e decretos. Para tanto, tomaremos como fonte de pesquisa as prescrições educacionais contidas nos programas de ensino, publicados através de portarias da Secretaria de Estado da Educação e manuais pedagógicos produzidos para uso nos cursos de formação de professores primários, destinados à disciplina de Prática de Ensino/Metodologia e Prática do Ensino Primário, entendendo-os como dispositivos mediadores entre as normas legislativas e a prática docente. Essas fontes configuram um repertório de conhecimentos profissionais, pois reguladas pelo campo doutrinário prescrevem modos para torná-los praticáveis. Pretende-se fazer a análise sob a luz do referencial teóricometodológico da História Cultural, que proporciona o embasamento para pensar as práticas sociais e pedagógicas como componentes importantes das concepções teóricas e como elementos de consolidação das ideias em circulação. A análise está baseada nos programas de ensino para o curso de formação de professores publicados em 1953, 1954, 1958 e 1960 e, também, nos manuais didáticos: Noções de Prática de Ensino (1951) e Metodologia do Ensino Primário (1952), de Theobaldo Miranda Santos. Tais fontes permitem a compreensão de diferentes apropriações por meio das quais a renovação pedagógica foi posta em circulação, estabelecendo continuidades práticas e contribuindo para a incorporação de saberes à cultura escolar.
\end{abstract}

Palavras-chave: Circulação de Ideias. Escola Nova. Manuais Pedagógicos. Programas de Ensino. Prática de Ensino.

\author{
Manuela Priscila de Lima Bueno \\ Universidade Estadual Paulista - \\ UNESP - Brasil \\ manuela.mplb@gmail.com
}

\section{Para citar este artigo:}

BUENO, Manuela Priscila de Lima. Manuais pedagógicos e programas de ensino: interpretações da Escola Nova sobre a prática de ensino na formação de professores (1946-1961). Revista Linhas. Florianópolis, v. 18, n. 38, p. 264-291, set./dez. 2017. 


\title{
Teaching manuals and teaching programs: interpretations of the new school movement about the teaching practice in teachers training courses (1946 - 1961)
}

\begin{abstract}
This study intends to contribute to the understanding of the ideas circulation movement of the New School, in the state of São Paulo, between 1946 and 1961, considered by historiography as a period of consolidation of the New School guidelines in the regulatory framework of laws and decrees. To this end, we will take as a research source the educational guidelines contained in the syllabus published by the State Department of Education and the teaching manuals produced for use in training courses for primary school teachers. These manuals prepared for the Teaching Practice / Methodology and Practice of Primary Education Course are understood as mediators between legislative norms and teaching practice. These sources make up a repertoire of professional knowledge, once such manuals are legally regulated and prescribe ways to make them feasible. We intend to make the analysis in light of the theoretical and methodological framework of the Cultural History, which provides the basis for a reflection about social and pedagogical practices as important components of theoretical conceptions and as consolidating elements of the ideas in circulation. The analysis is based on the teaching programs for the teacher education course, published in 1953, 1954, 1958 and 1960 , as well as on the textbooks Teaching Practice Notions (1951) and Methodology for Primary Education (1952), by Theobaldo Miranda Santos, and Summary of General Teaching (1957), by Luiz Alves de Mattos. Such sources allow the understanding of different appropriations through which the pedagogical renewal was put into circulation, established practical continuities and contributed to the incorporation of new abilities to the school culture.
\end{abstract}

Keywords: Circulation of Ideas. New School. Teaching Manuals. Teaching Programs. Teaching Practice. 


\section{1 - Introdução}

A circulação de ideias da Escola Nova tem sido objeto e tema de constantes discussões nas pesquisas acadêmicas. Para Monarcha (2009), os estudos sobre o movimento representam um painel que não se fecha, já que seus desdobramentos alcançaram inúmeras ramificações no campo da cultura que geram, nos dias de hoje, diferentes perspectivas de estudo. Como aponta Carvalho (2003), fazem-se necessárias análises sobre a Escola Nova que considerem seus usos sociais, suas apropriações e desdobramentos para além da discussão do embate entre católicos e renovadores e para além das análises que privilegiam autores já consagrados do movimento e os desdobramentos normativos advindos dele na década de $1930^{1}$.

Analisar a Escola Nova, portanto, é transitar pelos caminhos variados que o movimento suscitou em virtude de sua influência na educação brasileira. Adotamos, nesse sentido, a categorização proposta por Escolano $(2006)^{2}$ para verificar as articulações estabelecidas entre as prescrições contidas nos programas de ensino, elaboradas pelos órgãos oficiais, e as mediações produzidas por autores de manuais, tendo por objetivo a formação de professores em novas bases.

Sendo assim, o presente artigo pretende compreender os sentidos conferidos às prescrições práticas depois de 1930, focalizando os direcionamentos práticos dos cursos de formação de professores primários e, mais especificamente, as matérias de Prática de Ensino/Metodologia e Prática do Ensino Primário.

O recorte temporal adota dois marcos legais: o primeiro datado de 1946, quando foi instituída a Lei Orgânica do Ensino Normal, Decreto $n^{\circ} 8.530$, de 2 de janeiro, que reordenou essa modalidade de instrução após o Estado Novo, com o objetivo de dar uniformidade e nivelar a formação em todo o país. Já o marco final corresponde à Lei de Diretrizes e Bases da Educação, Lei Federal n 4.024, de 20 de dezembro de 1961, quando

\footnotetext{
${ }^{1}$ Essas análises já se fazem representativas no campo da história da educação com alguns trabalhos: VIDAL 2001; VALDEMARIN, 2010; SILVA 2001 e 2006; LABEGALINI, 2005, entre outros.

${ }^{2} \mathrm{O}$ autor categoriza a cultura escolar em quatro grandes âmbitos, englobando as estruturas organizativas da escola; os atores, especialmente alunos e professores; o programa (currículo); e as mediações no tocante às relações de ensino e aprendizagem. Consideramos, portanto, que no âmbito do programa estariam os documentos normativos, como a legislação e os programas de ensino, e no das mediações estariam os modos e procedimentos de ensino, junto aos materiais de uso escolar, como os manuais pedagógicos.
} 
novas concepções pedagógicas começaram a ganhar representatividade no cenário nacional, indicando mudanças significativas para o curso de formação de professores, inclusive enfatizando a base comum de matérias para o ensino secundário e não mais as especificidades da formação profissional do professor. Entre esses dois marcos, tomaremos em conta as regulamentações legislativas do Estado de São Paulo que, em tese, deveriam submeter-se às prescrições federais, fazendo as adaptações necessárias.

As fontes adotadas foram a Coleção de Leis e Decretos do Estado de São Paulo e os seguintes programas de ensino: Programas das escolas normais do Estado de São Paulo, publicado pela Editora J. Bignardi \& Cia. Ltda., em 1953; Programas das Escolas Normais e Instruções Metodológicas, publicado pela Editora do Brasil, em 1954; Programas do Curso Normal comunicado pela chefia do ensino secundário e do curso normal, publicado pela Editora do Brasil, em 1958; e Programas dos cursos do Ensino Normal, de 1960, divulgado pela Divisão de Relações Públicas na publicação avulsa número 4. Além disso, foram selecionados dois manuais pedagógicos destinados ao ensino da matéria de Prática de Ensino/Metodologia e Prática do Ensino Primário: Metodologia do Ensino primário, de Theobaldo Miranda Santos (Companhia Editora Nacional, $3^{\text {a }}$ edição, 1952), e Noções de Prática de Ensino, de Theobaldo Miranda Santos (Companhia Editora Nacional, $2^{\text {a }}$ edição, 1951), que, segundo Silva (2001), foram dos mais expressivos, no período aqui delimitado quando se considera o número de edições - com sete cada um - e a inserção em coleções especialmente destinadas para a formação de professores.

Tais fontes servem ao propósito de analisar um período no qual os embates iniciais sobre a renovação pedagógica já haviam arrefecido e as concepções já haviam sido sedimentadas em termos legais, denotando as apropriações e os significados plurais, crivados por consensos e contradições, adquiridos pelo movimento.

Para empreender as análises propostas, utilizaremos três conceitos advindos das orientações teórico-metodológicas da História Cultural: apropriação, estratégia e tática. De acordo com Certeau (1994), por apropriação, entendemos os consumos combinatórios e utilitários da cultura que revelam formalidades práticas, a partir de um quadro de representações já instituídas, imprimindo maneiras de utilização dela; por estratégia, entendemos a manipulação da relação de forças por um sujeito ou instituição de poder, no sentido de gerir relações sem alvos ou ameaças externas; e, como tática, 
entendemos as formas criativas de lidar com as estratégias, isto é, desembaraçar-se em uma rede de forças estabelecidas. Objetivando esclarecer as ênfases formativas dos cursos de formação de professores primários, cabe salientar a centralidade de algumas ideias que ganharam terreno com a discussão e a disseminação do ideário escolanovista no país para, então, adentrar pelas análises pretendidas.

\section{2 - A prática de ensino para a formação de professores primários na perspectiva dos dispositivos legais: entre renovação e resistências}

Como Monarcha (2009), Saviani (2008) e Valdemarin (2006) pontuam, algumas noções provindas das influências da Escola Nova ganhariam destaque no contexto brasileiro e paulista para a formação de professores primários, dentre elas as da psicologia da educação, que se desdobraram, por exemplo, nos testes de aferição da inteligência; a de adequação do conteúdo à maturidade e aos interesses da criança; e as de prática de ensino, objetivando que os alunos normalistas pudessem experimentar situações mais próximas da realidade escolar, com embasamento teórico e orientação metodológica.

A prática de ensino se constituiu como área central da profissionalização do professor primário a partir de 1930, fosse ela definida como disciplina do currículo, como prescrição de atividades consideradas formativas ou como princípio organizador do curso. Ela não era novidade no currículo do ensino normal, mas com a Escola Nova ganhava projeção e outra perspectiva para a formação técnica do professor, não restrita à observação. A prática de ensino foi concebida sob a égide do ensino ativo, devendo ser reflexiva e centrada no interesse da criança, sendo esta sujeito construtor de sua própria experiência (SÃO PAULO, 1933).

Deveria também consolidar as diretrizes sociológicas, psicológicas e biológicas explicitadas nas matérias constantes do currículo, por meio do emprego de métodos e processos de ensino, para garantir significado às proposições teóricas. No Estado de São Paulo, a ênfase na renovação educacional foi alicerçada no Código de Educação (SÃO PAULO, 1933), redigido por Fernando de Azevedo e promulgado em 1933 por meio do Decreto $n^{\circ} 5884$. Esta normativa organizou os diferentes níveis de ensino de acordo com as mudanças pretendidas e demarcou para a formação do magistério primário o Instituto 
de Educação Caetano de Campos como lugar de disseminação de novos modelos, estabelecendo o padrão para a organização administrativa e pedagógica das instituições paulistas entre 1940 e 1960.

Como modelo e aspiração, o decreto propôs um curso normal com três anos de duração, elevado a nível superior, com estágios obrigatórios na escola primária anexa, visando a experimentação e a aplicação das ciências da educação e dos métodos específicos das matérias do ensino primário. A seção Prática de Ensino foi dividida em duas subseções: prática de ensino e matérias de ensino. Estas comportariam o estudo dos conteúdos e o modo de transformá-los em prática, de acordo com métodos e processos específicos; aquela coordenaria a execução dos métodos estudados por meio da observação, experimentação, e participação no ensino primário. Dadas suas características, o Instituto de Educação foi incorporado à Universidade de São Paulo em 1934 (EVANGELISTA, 2002).

Pelo mesmo decreto de 1933, as Escolas Normais existentes no estado, porém, ficaram com uma estrutura organizacional e curricular mais simples que o Instituto de Educação: com um curso de dois anos e de nível médio, sem prescrições específicas para os estágios de prática de ensino, com poucos recursos para desenvolver as metodologias específicas e, ainda assim, deveriam acompanhar a renovação adaptando-a aos recursos e condições existentes.

Em decorrência desse decreto, a formação de professores passou a ocorrer em dois níveis diferentes de ensino, sendo observadas também discrepâncias na ênfase dada à prática de ensino. Mas, em linhas gerais, a prática de ensino deveria intermediar a relação entre os elementos teóricos e práticos do currículo, desenvolvendo atitude científica, munindo os normalistas, tanto do Instituto de Educação quanto das Escolas Normais, de um saber técnico e instrumental, tornando-os capazes para a resolução de problemas práticos no trato com os alunos, no planejamento escolar e nas ações desenvolvidas em sala de aula.

Com a instauração do Estado Novo, em 1937, e diante do cerceamento imposto pelos embates travados na década de 1930 sobre a Escola Nova, o Instituto de Educação Caetano de Campos foi extinto em 1938 e uma parte de seus professores passou a integrar a Faculdade de Filosofia, Ciências e Letras da Universidade de São Paulo e outra 
parte passou a constituir a Escola Normal Modelo. A formação do magistério primário no estado voltou a ficar, exclusivamente, a cargo das Escolas Normais, a partir de então. Elas ficaram regulamentadas pelo Código de Educação e pelo Boletim no 17 (SÃO PAULO, 1938), que estabeleceu o programa de ensino a ser seguido, fixando, assim, linhas mestras de orientação para o trabalho no ensino normal.

Neste Boletim, o programa de Prática de Ensino foi reconfigurado e adquiriu maior detalhamento, estabelecendo-se que a formação profissional deveria obedecer a uma sequência de três fases: observação, participação nos trabalhos escolares e governo autônomo da classe. A participação dos estudantes normalistas nas atividades da escola primária progredia da preparação de material para o ensino, organização de excursões, museus escolares e bibliotecas para as atividades relacionadas aos conteúdos mais essenciais: alfabetização, ensino da leitura, linguagem oral e escrita, adaptação do horário e do programa ao sistema de projetos, considerando os programas de ensino do curso primário e a familiarização dos futuros professores com aspectos administrativos e técnicos do magistério. Além da convergência das diferentes disciplinas para pesquisas sobre o ambiente social e para o estudo do meio.

Tal programa estabeleceu o objetivo da escola normal como espaço de formação de técnicos do ensino primário por meio da observação de bons modelos, do treino pessoal e do estudo de noções teóricas das ciências e fundamentos da educação, já que seria da escola normal que se disseminariam as práticas e as ideias novas. No tocante às matérias prescritas, vale salientar o estudo das noções de psicologia aplicáveis à educação; a divisão da matéria de Pedagogia em Pedagogia Científica e Pedagogia Filosófica; o estudo das escolas novas pela matéria de História; as investigações e pesquisas do meio pela matéria de Sociologia; e a observação, participação e governo autônomo da classe primária pela matéria de Prática Ensino.

Após 1938, essa concepção para a formação de professores adquiriu estabilidade, sem grandes reformas legais ou diretrizes orientadoras no Estado de São Paulo até a promulgação da Lei Orgânica do Ensino Normal (Decreto-Lei $n^{\circ} 8.530$, de 2 de janeiro de 1946), de âmbito federal. Depois das disputas em torno da hegemonia do discurso pedagógico e do período de controle das ideias no Estado Novo, ficou estabelecido, a partir de 1946, portanto, que o curso de formação de professores primários ficaria a 
cargo das Escolas Normais e dos Institutos de Educação que, obrigatoriamente, deveriam manter anexo um grupo escolar, no qual se dariam a experimentação e a prática de ensino. Ambas as instituições se situavam no nível médio e deveriam ser equiparadas em termos de currículo, conteúdo e objetivos para a formação de professores primários.

A primeira regulamentação paulista após a Lei Orgânica do Ensino Normal foi instituída pelo Decreto n 17.698, de 26 de novembro de 1947, que, no entanto, pontuava: "as normas consolidadas não revogarão dispositivo algum da legislação vigente, no caso de incompatibilidade entre os textos respectivos" (SÃO PAULO, 1947, p. 265), esclarecendo tratar-se de uma atualização e complementação das leis estaduais já existentes, destinadas a unificar a legislação educacional no estado e sem menção sobre a regulamentação federal instituída no ano anterior.

Apesar da não revogação do Código de Educação de 1933, pode-se perceber que as ideias irradiadas por ele foram enfraquecidas: o quadro de matérias dos Institutos de Educação passava a englobar conteúdos de conhecimento próprio dos cursos médios e a formação de professores primários se fazia por duas vias: a das escolas normais - focada nas ciências da educação - e a dos Institutos de Educação - abrindo espaço ao estudo da metodologia específica de cada disciplina do ensino primário, bem como para a formação de caráter geral, comum aos cursos de nível médio.

Nas Escolas Normais, a disciplina era a Prática de Ensino, nos Institutos de Educação denominava-se de Metodologia e Prática do Ensino Primário, porém, elas se equivaliam pelos mesmos objetivos, pela carga horária predominante em relação às outras matérias e pela obrigatoriedade do curso primário anexo para a realização dos estágios. Observa-se nos currículos a centralidade ocupada por elas como momento de observação, participação e experimentação, tendo como diretriz os métodos e processos de ensino nos termos da educação renovada. Para ambos os cursos realizar-se-ia o estudo dos métodos e processos de ensino referentes a cada matéria. Todavia, a presença de matérias do ensino primário nos Institutos de Educação marcava o caráter específico que cada uma delas possuía em relação ao método e também na formação anunciada como modelar, talvez por isso a importância do termo metodologia associado à prática. Já para as Escolas Normais, a ênfase metodológica dava-se somente no âmbito das matérias de 
ciências da educação, ficando as metodologias específicas das matérias do ensino primário sem espaço formal no currículo.

Os textos legais corroboram os indícios de que havia resistência, no estado de São Paulo, para adotar a legislação nacional. Os programas de ensino, que materializariam as instruções legais com prescrições de conteúdo para o currículo firmado, só foram publicados sete anos depois da promulgação da Lei Orgânica do Ensino Normal e seis anos após o Decreto $\mathrm{n}^{\circ}$ 17.698/47. Em 1953, foram publicados os Programas das Escolas Normais do Estado de São Paulo e, em 1954, os Programas das Escolas Normais e Instruções Metodológicas, pela Secretaria de Estado dos Negócios da Educação, por meio de portarias e disseminados através do Serviço de Legislação e Publicidade do Estado de São Paulo.

A alternância de tendências e a contradição entre prescrições ilustram o movimento de ideias para a formação do magistério. Os princípios firmados na década de 1930 foram prerrogativa e imperativo para alguns dispositivos legais surgidos a partir de 1940, atendendo à crescente demanda pela escola primária e, consequentemente, pela formação de professores para compor seus quadros. Tal tendência foi reiterada pelo programa de 1953, que é cópia do Boletim nº 17 nas prescrições de conteúdo, sem, no entanto, reproduzir os princípios propostos por sua introdução geral. O programa de 1954 fez o caminho inverso: declarou embasamento nos princípios gerais do referido boletim, mas alterou a forma de organização e o conteúdo proposto. Apesar das declarações fervorosas deste programa explicitando a importância das diretrizes expostas pelo boletim referido, o conteúdo prescrito para as disciplinas, principalmente aquelas das ciências e dos fundamentos da educação, foi reduzido, tornando-se menos específico.

Nos dois programas foi salientada a necessidade de articulação das demais disciplinas com a Prática de Ensino e a exigência de aplicação de conteúdos e da vivência dos alunos-mestres nas ações empreendidas nas escolas primárias anexas. Ressalta-se que do programa de 1953 para o programa de 1954 foi adicionado o estudo dos métodos de ensino concernentes a cada matéria presente no curso primário, que já era conteúdo para os Institutos de Educação. Deve-se considerar, no entanto, que os programas de 1953 e 1954 traziam também o conteúdo específico para o Curso Pré-normal, que foi 
instituído em 1944 como pré-requisito para a entrada nos cursos de formação de professores primários das Escolas Normais ${ }^{3}$ e abarcava matérias de caráter geral, comuns ao ciclo ginasial. Tal fato indica uma admissão velada de que os estudantes chegavam ao curso normal sem uma boa formação geral, demandando tal medida de complementação para a sequência e melhoria dos estudos. Nesse sentido, e dando indícios de possíveis mudanças na estrutura do ensino normal do estado, o programa de ensino de 1954 afirmou que aquelas prescrições eram "o primeiro passo para o exame objetivo dos problemas atuais do ensino normal com vistas à sua reforma futura" (SÃO PAULO, 1954, p. 20). Sendo assim, a inclusão de tais matérias no currículo possibilitava o estudo de seus métodos específicos e, simultaneamente, indicava as deficiências apontadas na formação.

Essa tendência de enfraquecimento das ideias e da estrutura proposta para o ensino normal culminou com a justificativa da Lei $3.739 / 57^{4}$, veiculada em 1956, apontando que a ausência de diretrizes comuns "tornou desiguais os regimes e as condições de estudo e de trabalho em escolas da mesma natureza, montadas para alcançar o mesmo objetivo" (SÃO PAULO, 1960, p. 9). Evidenciou-se ao longo das prescrições o esmorecimento de algumas ideias que, na década de 1930, tinham peso e definiam a aprendizagem por meio dos preceitos da Escola Nova: a pesquisa de campo, o trabalho como elemento formador do educando, a ênfase nos autores consagrados em matérias como Sociologia, Pedagogia e História da Educação, bem como visitas e excursões. A promulgação de muitos dispositivos revela a dificuldade em estabelecer diretrizes gerais por parte do estado, tendo em vista o aumento de instituições de ensino normal, o número de alunos e a dificuldade em firmar um currículo comum que atendesse a esse crescimento sem prejuízo às instituições.

A legislação, explicitamente, decreta a mudança de orientação para a formação de professores:

A estrutura dada em 1933 pelo Código de Educação ao ensino normal em São Paulo, desfigurada pela legislação posterior, superada também que

\footnotetext{
${ }^{3}$ Decreto-Lei $n^{\circ} 14.002$, de 25 de maio de 1944. O Curso Pré-normal foi extinto com a promulgação da Lei 3.739/57, que unificou o currículo das Escolas Normais e dos Institutos de Educação.

${ }^{4}$ Utilizou-se a versão do projeto de lei que está presente na publicação avulsa $n^{\circ} 4$, datada de 1960 , baixada pela Divisão de Relações Públicas do Estado de São Paulo - compêndio da legislação, publicada entre 1957 e 1960.
} 
foi pelas circunstâncias sociais e pedagógicas supervenientes, já não serve mais, como tão bem serviu anteriormente, às necessidades educacionais para cuja satisfação existe. (SÃO PAULO, 1960, p. 9)

Assim, as ideias caracterizadoras da renovação levada a cabo nos anos de 1930 perderam força nos ditames legislativos e a formação de professores primários passou a enfatizar as disciplinas de caráter geral e não mais as pedagógicas aliadas ao estudo dos métodos específicos, que haviam sido agrupadas e perderam espaço no currículo. A prática de ensino não foi modificada, continuava com os mesmos objetivos e seu conteúdo sofreu mínimas alterações. Entretanto, o contexto alterou-se e aquilo que se constituía como estratégia, isto é, a prática de ensino como centro das atividades do curso, perdeu seu lugar próprio e foi sendo descaracterizada pela formação comum preconizada para todos os cursos médios, tornando-se, ainda assim, o único espaço profissional, já que o espaço para as matérias pedagógicas foi reduzido e seu conteúdo ressignificado. Observa-se a ênfase na prática de ensino como momento de aplicação e não mais de estudo de métodos embasados nas ciências e fundamentos da educação. A formação de caráter geral do professor, comum a todos os cursos de nível médio, começava a ser evidenciada e preconizada na nova legislação:

b) - extensão às escolas normais do mesmo currículo ora existente nos institutos de educação do Estado, e que nos parece melhor, pois apresenta conteúdo mais rico de cultura geral e isto é o de que mais carece o diplomado pelas escolas normais comuns, onde a preocupação dominantemente, senão exclusivamente pedagógica, tem feito esquecer, comumente os demais. (SÃO PAULO, 1960, p. 11)

O quadro foi alterado com a promulgação da Lei $n^{\circ} 3.739$, de 22 de janeiro de 1957 e, a partir de então, o ensino normal ficaria a cargo das Escolas Normais e Institutos de Educação que passariam a ter objetivos e organização comuns, tanto como instituição formadora de professores primários, quanto como referência ao currículo em um curso normal de três anos para ambos 5 . Dessa forma, a prática de ensino nas suas diversas

\footnotetext{
${ }^{5}$ Até então, as Escolas Normais possuíam o curso de formação de professores primários com duração de dois anos. A denominação dos cursos para formar professores primários também era diferente: nas Escolas Normais, era o Curso de Formação de Professores Primários e, nos Institutos de Educação, denominava-se Curso Normal.
} 
facetas se unificava em termos das proposições metodológicas e também em termos de disciplina constante do currículo do curso normal, bem como em sua articulação com o restante do currículo.

Portanto, ela apareceu em dois momentos temporais, no período delimitado para análise, ao longo de sua trajetória no Estado de São Paulo: quando se constituiu em matérias com denominações distintas e em instituições diferenciadas, entre 1947 e 1957; e após o Decreto $n^{\circ} 3.739$, de 1957, em que o currículo dos Institutos de Educação e das Escolas Normais foi unificado, sendo priorizado aquele referente aos institutos e a denominação de Metodologia e Prática do Ensino Primário.

O novo quadro de matérias evidenciava o afrouxamento das diretrizes pedagógicas do curso, o esvaziamento da formação profissional do professor e a perda de força política das ideias pedagógicas de 1930, levando em conta que a maior parte do currículo foi dedicada às matérias de formação geral, apesar da orientação para o estudo de seus métodos e processos de ensino. A carga horária estabelecida nos dois anos do curso normal, após 1958, evidencia que o número de aulas na somatória das matérias de formação pedagógica não ultrapassava 36 aulas semanais, enquanto o de matérias de formação geral chegou a 45 aulas semanais. Para regulamentar as mudanças foram publicados outros dois programas de ensino para a formação dos professores primários datados de 1958 e 1960. Assim como os de 1953 e 1954, eles indicavam pontos a serem tratados em cada matéria, a carga horária e a divisão dos conteúdos pela série.

Deve-se salientar também, no tocante à ênfase técnica da formação de professores primários, que algumas matérias foram agrupadas, como o caso da Psicologia Educacional e da Pedagogia e que a carga horária diminuiu: na legislação referente aos programas de 1953 e 1954, a somatória das citadas acima era de 13 aulas semanais; quando elas foram unificadas e regulamentadas pelos programas de 1958 e 1960, o total de aulas semanais foi, respectivamente, de sete e nove. A mesma observação se aplica às outras disciplinas pedagógicas, significando mais pontos a serem tratados, porém em menos tempo.

Observando a composição dos conteúdos para a prática de ensino nos quatro programas citados, pode-se afirmar que, em termos metodológicos, as inovações pretendidas sedimentaram-se no currículo e nas prescrições para a prática, prevendo o 
método de projetos, os centros de interesse, o trabalho com unidades didáticas, mas, no referente aos princípios da formação por meio do trabalho e da pesquisa, as pretensões e prescrições esvaíram-se.

O que mais chama atenção é o desaparecimento, ao longo do tempo, do termo Escola Nova. Em 1953, a prescrição para as matérias de Psicologia e de Pedagogia era do estudo das características das escolas novas, ativas e progressivas, fazendo a comparação delas com a escola tradicional; em 1954, o programa prescreveu o estudo da visão geral sobre a Escola Nova. Já em 1958 e 1960, os programas de ensino da disciplina Pedagogia e Psicologia Geral e Educacional não faziam menção a qualquer estudo sobre o movimento, centrando a preocupação nos processos de ensino, portanto, no planejamento, na motivação da aprendizagem, nos métodos de ensino e na avaliação da aprendizagem. É relevante ressaltar também que os Testes $A B C$ apareceram somente no ano de 1953; em 1954 e 1958, a prescrição foi para a mensuração da inteligência do educando, sem fazer menção aos testes e, nessa tendência de esvaziamento dos pontos que a Escola Nova chamava a atenção no Brasil, o programa de 1960 não mencionou nenhum tipo de aferição da inteligência dos educandos no programa da matéria.

Na disciplina de História, que posteriormente foi chamada de Filosofia e História da Educação, o termo aparece até o programa de 1958. Em 1953, apareceu com grande ênfase, inclusive citando alguns autores para estudo, como Dewey, Decroly, Ferrière e Montessori, e previu o estudo do manifesto dos educadores brasileiros; em 1954, o programa de ensino recomendava o estudo da renovação pedagógica de 1930, considerando ser seu desdobramento a Lei Francisco Campos, o manifesto dos pioneiros e a expansão da rede educacional, bem como o problema das bases e diretrizes da educação nacional; em 1958, foi prescrito o estudo da Filosofia da Escola Nova, a influência de Dewey e de educadores brasileiros; em 1960, não há menção à Escola Nova nem aos seus autores, prevendo somente o estudo da visão histórica da educação no Brasil.

Em 1953 e 1954, os programas de ensino para a matéria Biologia Educacional direcionaram a disciplina para o entendimento do fenômeno educativo, indicando conteúdos como: elementos que auxiliassem em outras matérias do curso, estudos sobre natalidade e mortalidade, problemas práticos relacionados à matéria e uma sala ambiente 
de Biologia, onde constassem os estudos feitos, bem como a prática de noções de enfermagem a ser realizada em visitas a instituições de saúde. Já para Anatomia e Fisiologia Humanas, Higiene e Biologia Educacional, nos programas de 1958 e 1960, essas prescrições gerais, de teoria e de prática pedagógica relacionadas com a biologia, não apareceram e a ênfase, portanto, ficou nos conteúdos especificamente relacionados à biologia como matéria geral, dando algum destaque para o desenvolvimento dos alunos pré-escolares e escolares.

A matéria de Sociologia Educacional, denominada posteriormente de Sociologia Geral e Educacional, também perdeu itens que compunham o movimento de ideias da Escola Nova. O fato de mudar a denominação que especificava sua função no currículo e adicionar o caráter geral já é um indício da diminuição dos conteúdos pedagógicos. Em 1953 e 1954, o trabalho prático de pesquisas de campo foi central no currículo da matéria. Havia a prescrição para os field works, isto é, os trabalhos práticos para ensinar a observar e fazer pesquisas sobre o meio local com sugestões para despertar e orientar investigações sociológicas. A pesquisa de campo em 1958 e 1960 desapareceu, mantendose alguns estudos de base teórica como a função social da escola, o papel do conhecimento sociológico e a escola como grupo social, mas não mais as pesquisas de campo ou os inquéritos para as investigações sociais.

A matéria Metodologia e Prática de Ensino, ainda assim, teve ditames comuns ao longo dos anos, sem significativas alterações até 1960. Entretanto, já que ela era considerada o eixo no qual gravitavam as outras matérias, torna-se necessário pontuar que a diminuição dos conteúdos de formação profissional do professor referentes à formação pedagógica e técnica do professor primário, acabou por indicar o enfraquecimento no modelo proposto incialmente, apesar das tentativas de mantê-lo vivo durante a década de 1950. As ressonâncias que ecoavam das décadas anteriores perdiam a intensidade, arrefeciam-se, e os ditames que davam ênfase ao planejamento do ensino sobressaíam, dando ares eminentemente pragmáticos para a prática de ensino e diminuindo o embasamento teórico e o estudo sobre as questões educacionais previstos até então.

Com a ocasião da Lei $n^{\circ}$ 4.024, de 20 de dezembro de 1961, que estabeleceu as diretrizes e bases para a educação nacional, houve o clamor pela formação de nível 
superior para os professores primários, que ganhava força juntamente com a ideia de tornar a escola eficiente e produtiva e, dessa forma, o Curso Normal começava a se descaracterizar como instância adequada para a formação do professor das séries iniciais nos moldes que até então se preconizava, já que a aspiração para a formação desses professores retomava a necessidade de formação superior para atuação no magistério primário.

É certo que a prática de ensino ganhou destaque na formação de professores e foi alvo das estratégias legislativas referentes ao ensino normal no Estado de São Paulo. As diretrizes e conteúdos para a prática de ensino avultavam possibilidades de articulação entre teoria e prática, por meio dos métodos e processos de ensino. Ela não se constituiu somente como disciplina ou ação, mas como ideal educativo que, por sua vez, criou estratégias e práticas simbólicas, determinando posições e relações que construíram identidades. A identidade criada proporcionou caráter científico e pedagógico-didático para a formação de professores primários, apesar do enfraquecimento das disciplinas pedagógicas no currículo.

Significando a cultura escolar nos termos dos saberes pedagógicos e das prescrições práticas desses cursos de formação, as disposições práticas possuíam três momentos: o da teoria, o dos métodos e processos de ensino e o da prática. Para a teoria, ficavam os princípios das ciências da educação e seus aspectos históricos e filosóficos; para os métodos e processos de ensino, ficavam as diretrizes de ação prática, apontando caminhos possíveis de intervenção; e para a prática de ensino, ficariam as atividades e as ações interventivas dos alunos-mestres nas escolas anexas, incluindo observação, participação e experimentação.

Então, se a estratégia se define pelo "[...] cálculo das relações de forças que se torna possível a partir do momento em que um sujeito de querer e poder é isolável de um 'ambiente"' (CERTEAU, 1994, p. 46), a prática de ensino na legislação e nos programas, entre 1946 e 1961, foi uma estratégia que ganhou lugar próprio pela singularidade e importância que as ideias veiculadas à época atribuíram a ela. 


\section{3 - Os manuais pedagógicos para a prática de ensino}

As ideias da Escola Nova desenvolveram um repertório pedagógico, sugerindo modos de uso e produzindo "versões praticáveis da teoria nas condições específicas da escola brasileira daquele tempo" (VALDEMARIN, 2010, p. 131). Para chegar até o ponto das prescrições práticas nos livros didáticos, as concepções da Escola Nova já haviam passado pelo crivo de aceitação por parte do meio intelectual e das figuras políticas, resultando em leis, decretos e programas de ensino, para então ser objeto de reflexão, a partir da delimitação do campo de estratégias normativas, dos manuais pedagógicos e das possíveis práticas que seus autores julgaram pertinentes. Sendo assim, eles foram produtores de significados, ao mesmo tempo em que foram produtos de diversas apropriações decorrentes da difusão do ideário. Para Choppin (2002, p. 14) “em primeiro lugar, o livro de classe situa-se na articulação entre as prescrições impostas, abstratas e gerais dos programas oficiais - quando existem - e o discurso singular e concreto, mas por natureza do efêmero, de cada professor na sua classe".

A centralidade deles como material didático de grande circulação foi evidenciada por Silva (2001), que aponta o montante de coleções e de publicações na cena nacional entre 1940 e 1960, assim como o número de edições e as iniciativas editorias envolvidas ${ }^{6}$. De forma mais abrangente, Alain Choppin (2004) define a existência de duas categorias de pesquisa concernentes ao manual pedagógico: a primeira que o concebe como documento histórico, analisando seus conteúdos em busca de informações estranhas a ele mesmo, ou as que só se interessam pelo conteúdo ensinado por meio do livro didático; e aquelas que o consideram como um objeto físico, um produto fabricado com vistas a certos usos.

Aqui, os manuais pedagógicos foram analisados a partir de seus conteúdos, objetivando-se compreender as relações estabelecidas com as prescrições legislativas e os programas de ensino. Mas não se trata de tomar os manuais apenas como respostas às normas legais e desconsiderar as estratégias empreendidas por eles. Trata-se de analisálos considerando que táticas podem revelar-se preponderantes, se confrontadas com as prescrições legislativas, evidenciando diferentes modos de apropriação. Silva (2001)

\footnotetext{
${ }^{6}$ A autora localizou 44 títulos, que variaram entre 7 e 17 publicações/edições.
} 
marca três momentos concernentes à circulação dos manuais pedagógicos, que abrangem os livros selecionados aqui:

[...] situado entre os anos de 30 até 1946, observou-se já nos títulos e índices das obras a atenção voltada para a explicação dos postulados da Escola Nova. A partir de finais dos anos 40 , diferentemente, as questões metodológicas começaram a receber um espaço mais privilegiado, estando presente nos nomes dos livros e constituindo-se como temas dos capítulos desenvolvidos nos compêndios. Essa tendência acentuou-se nas décadas de 60 e 70, com as descrições sistemáticas relativas às técnicas pedagógicas [...]. (SILVA, 2001, p. 223 - grifo nosso)

Vale destacar, portanto, alguns pontos característicos de cada livro, bem como de seu autor. O manual pedagógico Noções de Prática de Ensino, de Theobaldo Miranda Santos, fez parte da Coleção Curso de Psicologia e Pedagogia da Companhia Editora Nacional, sendo o seu nono volume, e teve sete edições entre os anos de 1949 e 1967 (SILVA, 2001). É composto por 330 páginas, em sua $2^{\text {a }}$ edição, e o autor advertia que o livro se destinava aos estudantes de pedagogia, com o objetivo de iniciar os alunos dos Institutos de Educação e das Escolas Normais nos problemas da técnica pedagógica. E, ainda, "na serena convicção de que a prática de ensino é fruto, não de fórmulas pedagógicas ou de receitas didáticas, mas da atividade criadora do professor, nos limitamos, nêste compêndio, a resumir os princípios gerais que devem orientar o trabalho docente" (SANTOS, 1951, p. 7). Metodologia do Ensino Primário de Theobaldo Miranda Santos também fez parte da Coleção Curso de Psicologia e Pedagogia da Companhia Editora Nacional e teve sete edições até 1964. A edição utilizada aqui é a terceira, que corresponde ao ano de 1952 e ao décimo volume da coleção. O livro foi dividido em duas partes ao longo de suas 246 páginas: Metodologia Geral e Metodologia Especial.

Theobaldo Miranda Santos qualificava-se como escritor de manuais a partir do exercício da profissão docente em nível superior, formando especialmente o quadro do magistério secundário. Tal informação vinha disposta na folha de rosto de seus livros como um argumento de autoridade que ratificava o conteúdo e as práticas prescritas, legitimando os manuais pedagógicos.

Ele nasceu em 1904 na cidade de Campos, no Rio de Janeiro, e faleceu em 1971. Formado pela Escola Normal Oficial de Campos, ocupou inúmeros cargos na esfera 
pública e educacional e, dentre eles, foi professor da cátedra de Prática de Ensino na Universidade do Distrito Federal, assumindo por duas vezes a função de Secretário Geral de Educação e Cultura da Prefeitura do Rio de Janeiro. Também escreveu artigos para revistas e jornais, além de mais de 150 obras em formato de livro e seus manuais pedagógicos foram, em grande parte, destinados aos cursos normais com três coleções na Companhia Editora Nacional: Curso de Psicologia e Pedagogia, Curso de Filosofia e Ciências, e Atualidades Pedagógicas (ROBALLO, 2007).

Roballo (2007) afirma que este autor publicava os manuais pedagógicos como resultado das anotações de experiências docentes. Theobaldo tem a especificidade da filiação com os ideais católicos de educação, explicitada, principalmente, nos manuais de ciências e fundamentos da educação. Nos manuais utilizados aqui, o viés católico não aparece explicitamente no texto, a não ser pelas referências católicas elencadas, ou quando Santos (1951) afirma que se devem adotar os métodos renovados sem se filiar aos seus princípios metafísicos, dando indícios de possíveis divergências nos princípios filosóficos.

Porém, se há a presença de referências católicas indicadas pelos livros é porque, de alguma forma, há também a ressonância dessas leituras no texto. De qualquer maneira, o que sobressai é o fato de que o movimento da Escola Nova foi apropriado por diversos atores que deram a ela diferentes interpretações, significando o campo das práticas. No período de publicação dos manuais aqui analisados, a disputa entre católicos e liberais já havia perdido a força, com ganhos obtidos pelas duas vertentes.

Entre estratégias e táticas, o papel do manual pedagógico se alternou desde a sua produção até as suas apropriações pelos leitores, nas interpretações e na prescrição de modos de fazer. Nos contextos delimitados aqui, eles adquirem funções estratégicas quando direcionados a um público específico, prescrevendo intervenções práticas e moldando/reinterpretando a teoria de acordo com os saberes circulantes e as experiências do autor. Ao mesmo passo, assumem funções táticas quando respondem criativamente às normativas da legislação e dos programas de ensino, significando saberes e práticas de acordo com espaços específicos e com as contingências cotidianas da formação de professores primários. 
A prática de ensino existia na simbiose com as outras matérias conferindo-lhes significado por meio da aplicação de métodos e processos. Chave para o funcionamento do curso de formação de professores primários, ela só poderia se estabelecer com base na teoria que, tanto as matérias de fundamentos da educação quanto as de ciências da educação proporcionavam. Nessa perspectiva, antes de qualquer prescrição de atitudes ou atividades, os manuais traziam explicações gerais sobre procedimentos práticos indicados que embasariam e justificariam a ação proposta. Essa disposição dos manuais é reflexo da pretensão de instrumentalizar o ensino, experimentando os métodos e processos nas escolas primárias anexas às instituições de ensino normal. Tais explicações estavam marcadas pela interpretação da legislação e pela interpretação do movimento de ideias que circulavam. Sendo assim, não eram unívocas e apresentavam variações nos sentidos teóricos e nas prescrições práticas.

A aprendizagem aparecia como conceito a ser desbravado nas páginas iniciais dos manuais selecionados, pois as publicações consideravam a mudança na estrutura do ensino por meio da educação renovada: o aluno passara a ser o centro das discussões. Haveria, portanto, a preconização para que o professor tivesse conhecimento das necessidades e interesses de seu aluno, centrando seu trabalho na aprendizagem como processo biológico, psicológico e social.

A partir dos objetivos estabelecidos se edificariam o planejamento do ensino e seus desdobramentos: desde a preparação do plano de curso até a verificação e retificação da aprendizagem. Os planos (de curso e aula) eram peças fundamentais para a aplicação dos métodos e processos de ensino, organizando-os de modo sistemático e devendo expor, de maneira geral, os objetivos, os conteúdos propostos, o material a ser utilizado, os exercícios práticos e os modos de avaliação da aprendizagem.

Os dois manuais propuseram esse ciclo docente, mas diferenciaram-se na sua exposição. Noções de Prática de Ensino centrou seus esforços para descrever e prescrever um plano de execução para a aprendizagem, salientando o passo a passo de suas etapas: preparação dos planos, desde o mais geral, envolvendo a previsão para todo o ano letivo, até os mais específicos como o plano de aula, contendo os centros de interesse ou o método de projetos; organização da sala de aula em grupos homogêneos, a partir da aferição da maturidade intelectual por meio dos testes de inteligência; motivação da 
aprendizagem; apresentação da matéria; fixação dos conteúdos; retificação e verificação da aprendizagem, sempre levando em consideração o manejo da classe e a disciplina dos alunos. Já Metodologia do Ensino Primário centrou esforços em como executar os planos, a partir das metodologias específicas e dos processos de ensino pertinentes a cada matéria, não propriamente propondo etapas para aprendizagem, como no caso do outro manual, mas indicando possibilidades de preparação e execução. Os manuais, portanto, são concebidos como elementos que se complementam, assim como as duas matérias presentes no currículo.

Santos (1951 e 1952) considerava três etapas para o planejamento: o programa de ensino, o plano de curso e o plano de aula. O programa de ensino seria aquele elaborado no âmbito legislativo, ficando o plano de curso e o plano de aula como parte do planejamento dos professores.

Nos dois manuais foi reforçada, em diversos momentos, a adequação do conteúdo à maturidade e às necessidades psicobiológicas da criança, por isso ganham importância a sondagem e a avaliação da aprendizagem: seriam elas que determinariam a passagem de um conteúdo para o outro, de acordo com o rendimento dos alunos. Caso a aprendizagem tivesse sido satisfatória o conteúdo seria seguido; se, pelo contrário, o professor identificasse falhas no processo de aprendizagem, seria necessário retificá-las.

Os manuais foram enfáticos no que diz respeito à motivação. Ela seria o prelúdio para despertar o interesse da criança pelo conteúdo, dando significação e tornando a aprendizagem mais prazerosa e relevante no decorrer do processo. No manual Metodologia do Ensino Primário, a motivação estava frisada nas metodologias especiais de cada matéria do currículo do curso primário, evidenciada de acordo com as técnicas de ensino propostas. Já em Noções de Prática de Ensino a motivação aparecia de forma mais geral, sem necessariamente relacionar-se às especificidades de cada matéria.

A atitude do professor no exercício do magistério também contaria como motivação: ele deveria ser claro, objetivo, ter boa linguagem, dominar os conteúdos, saber conduzir uma aula por meio das técnicas de manejo da classe, estabelecer rotina, mantendo a ordem e a disciplina dos alunos, além de saber como preparar o ambiente, garantindo a organização do espaço físico. Dessa forma, estariam garantidas a motivação e o ambiente propício para a aprendizagem. Em Metodologia do Ensino Primário essa 
questão aparece ao longo das prescrições dos métodos e das explanações teóricas, sem um item ou tópico específico como no outro manual. Segundo Santos, “o professor deve tornar a aula viva, agradável e atraente. Para isso, é preciso que ajuste o assunto a ser desenvolvido à experiência e aos interêsses dos alunos" (1952, p. 78). Dessa forma, o professor ganhava papel de articulador das condições propícias para que a aprendizagem acontecesse em ambos os livros.

Foram destacados também por Santos (1951 e 1952) os materiais didáticos. Em Noções de Prática de Ensino, eles apareceram junto às matérias de ensino e para cada uma delas há a prescrição de materiais específicos. Para o ensino de leitura, por exemplo, ele afirmava que "tão importante quanto o livro de leitura são, nas primeiras séries, os aparelhos de leitura, os cartazes, os cartões com sentenças, palavras e sílabas, os jogos de leitura, etc." (SANTOS, 1951, p. 135). No manual Metodologia do Ensino Primário há um item específico abordando os materiais didáticos, caracterizando-os como objetos que auxiliariam o professor a exercer sua função educativa.

Definidos os objetivos e o planejamento do ensino, o autor passava a discorrer sobre os métodos e processos. Em Noções de Prática de Ensino, Santos (1951) deu ênfase a cada matéria do curso primário em um dos itens do manual, depois de expor alguns “métodos modernos de educação". Discorreu sobre a importância, os objetivos, a motivação, a técnica e a prática de ensino de cada uma delas, sendo esta última composta pelas sugestões dos programas de ensino do curso primário. Como desdobramento do método, Santos (1951) enfatizava as técnicas de ensino. Para o ensino de Ciências Naturais, por exemplo, propunha:

Segundo Aguayo, o professor deverá, a princípio, dirigir a observação mediante perguntas e estímulos didáticos; depois apresentará modelos de observação, elaborados pelas crianças mais capazes, tirados de livros ou sugeridos pelo professor. (SANTOS, 1951, p. 247)

Em Metodologia do Ensino Primário, dedicou uma parte para esclarecer a questão do método e a outra para indicar a metodologia especial de cada matéria do ensino primário, reservando um tópico para discorrer sobre os "métodos ativos e escolas novas". Santos (1951 e 1952) prezava, em seus manuais, a construção de um saber 
metodológico e as suas possíveis ações com sugestões de atividades, levando em conta as técnicas modernas de ensino. Por vezes, mas não via de regra, frisando condutas e prescrições de atitudes em sala de aula.

Feitos esses apontamentos, pode-se discorrer sobre a ligação entre os programas de ensino e os manuais pedagógicos como desdobramentos culturais provenientes da circulação das concepções escolanovistas. Estes documentos faziam-se notáveis na tensão entre a prescrição de conteúdos específicos e a conformação das práticas por meio de prescrições de modos de fazer. Nesse sentido, foram pensados na articulação entre as duas instâncias componentes da cultura escolar, como proposta por Escolano (2006), entre o âmbito dos programas e o âmbito das mediações.

Considerando que as prescrições normativas para a prática de ensino não variaram significativamente no período proposto (1946-1961), na contramão do que se estabeleceu para as outras matérias, pôde-se elencar 12 prescrições-chave expressas nos programas de ensino da matéria Prática de Ensino/Metodologia e Prática do Ensino Primário para caracterizar e sistematizar pontos recorrentes nos quatro programas. Quais sejam: 1) questões de arranjo e organização da sala de aula; 2) aplicação de testes pedagógicos; 3) estudo dos programas primários - a partir de 1954, há a especificação do estudo dos programas do ensino primário associada à metodologia e prática de cada matéria do currículo constante desse nível de ensino; 4) planejamento do ensino; 5) organização de festas escolares/instituições paraescolares/instituições auxiliares; 6) escrituração escolar; 7) observação e prática nas escolas de experimentação; 8) comparecimento às reuniões pedagógicas - da escola, da inspetoria auxiliar e da Delegacia Regional; 9) organização do ensino primário no Estado de São Paulo; 10) prática de métodos modernos de ensino; 11) verificação de aprendizagem/avaliação; e 12) especificidades concernentes ao ensino rural.

É necessário frisar que os manuais pedagógicos do período circularam em diferentes regiões do país, como apontou Silva (2001). Isto significa que eles se destinavam não às prescrições específicas do Estado de São Paulo, mas às prescrições da Lei Orgânica do Ensino Normal de âmbito federal que dividia a parte metodológica e a parte prática do curso em duas disciplinas: Metodologia do Ensino Primário e Prática de Ensino. Tal divisão não acontecia no Estado, pois mesmo sob a denominação de Prática de 
Ensino, tomando como exemplo as Escolas Normais, o estudo dos métodos acontecia na esfera da própria disciplina, prevendo a maior articulação possível. Atendendo à lei de âmbito federal e prescrevendo pontos gerais em publicações diferentes sobre prática de ensino e/ou metodologia, os manuais alcançariam o público e as prescrições dos diferentes estados, mesmo que estas se diferenciassem em alguns pontos do currículo ou dos conteúdos listados pelos programas.

As duas publicações de Santos (1951 e 1952) analisadas aqui faziam referência direta às disciplinas que envolviam a metodologia e a prática de ensino, inclusive no título dos livros. Ainda assim, observa-se uma tensão estabelecida entre o currículo proposto para as instituições de formação de professores primários e as prescrições evidenciadas pelo autor. Os dois manuais de Santos (1951 e 1952) articulavam-se com alguns pontos dos programas de ensino, como o nome do livro e a sugestão de utilização dos programas do ensino primário como direcionamento prático.

O modo de abordar as questões do método em Noções de Prática de Ensino e Metodologia do Ensino Primário era por meio de prescrições passo a passo, apontando caminhos possíveis para atuação, quando expunham, por exemplo, diferentes métodos de educação escolar, citando diversos autores e direcionamentos práticos. O professor poderia adotar um deles ou fazer composições de acordo com as necessidades surgidas no exercício do magistério. Observa-se, nessa tendência, a criação de um discurso escolar sobre o método, que o definia, conceituava, dividia em fases e propunha procedimentos e ações no âmbito da escola primária, indo além do proposto pelos programas e ampliando o repertório de prescrições para a prática. As recomendações, portanto, garantiriam o sucesso na progressão das atividades, desde a preparação da aula até a verificação do ensino.

A adoção das concepções modernas de ensino foi prerrogativa para os dois manuais que reservaram itens e tópicos para essa discussão, elencando autores e indicando técnicas de ensino como descrito na seção anterior. Dispostas as preocupações com o método, os livros detiveram-se sobre as ações do professor em sala de aula, arrolando temas como manter a disciplina, como orientar atividades diversas (estudo dirigido, centros de interesse, tarefas, provas, etc.), a linguagem e a postura do professor no dia a dia e como considerar os interesses das crianças no processo de aprendizagem. 
Sendo assim, em parte, os manuais atenderam às determinações dos programas. No tocante às prescrições-chave, foram abarcados o planejamento do ensino, a prática de métodos modernos, questões de arranjo e organização de sala de aula, e a verificação e avaliação da aprendizagem. Quanto às disposições gerais contidas nos programas, os manuais abordaram a aprendizagem como processo biológico e social, considerando a maturidade e as necessidades da criança. Deve-se salientar também que as publicações de Santos (1951 e 1952) levaram em conta o estudo dos programas primários dispondo-os na forma do estudo dos métodos específicos de cada matéria. Entre um total de 12 pontos elencados são dispostos somente seis deles nos manuais de Santos. Isso pode significar que as estratégias de conformação dos conteúdos pelos programas de ensino não foram tão eficazes como pretendiam os legisladores, e que os manuais não necessariamente respondiam rigorosamente aos programas, sendo de maior relevância a questão do método e das fases da ação do professor sobre temas muito frisados pelas ideias em movimento, como a observação e a prática nas escolas de experimentação, a aplicação de testes psicológicos e o estudo da organização do ensino primário.

A escrituração escolar, o estudo ou estágios nas escolas rurais, o comparecimento às reuniões pedagógicas nem sequer foram pontos mencionados em nenhum dos dois manuais. A tática, portanto, de tomar algumas indicações das prescrições dos programas e, a partir delas, abrir o leque para discussões pertinentes aos interesses de conformação do campo educacional pelo autor, funcionou na ênfase do estudo do método, que foi exaustivamente tratado por Santos (1951 e 1952), e nas prescrições para o planejamento e execução do ensino pelo professor, também tratados com afinco pelos dois manuais analisados.

As tensões entre conteúdos normatizados e prescrições práticas, isto é, entre o âmbito dos programas e o âmbito das mediações criaram significados e apontaram um modelo de formação para o magistério primário, embasado na indicação de atitudes práticas referentes, principalmente, aos métodos de ensino e ao planejamento minucioso das ações do ciclo docente, considerando as necessidades psicológicas para a realização da aprendizagem. 


\section{4 - Considerações Finais}

Ao longo do período analisado aqui, as ideias pioneiras da Escola Nova, difundidas nos anos de 1930, sofreram um arrefecimento evidenciado, principalmente, pelas mudanças na legislação: perda do nível superior para a formação de professores primários, introdução de disciplinas de caráter geral no currículo, diminuição da carga horária e dos conteúdos das matérias de ciências e fundamentos da educação, redução das menções do termo Escola Nova e dos autores de referência, diminuição das propostas de pesquisa em torno das questões sociais. Ao mesmo tempo, ganhavam força as questões do método, mas não como propostas inicialmente, envolvidas com o embasamento teórico e experimentação, isto é, como um recurso a favor da aprendizagem nos moldes preconizados, mas como prescrição de normas, de passos formais para se chegar ao fim objetivado, já que se abrandou o clamor em torno das concepções da Psicologia, Pedagogia e Sociologia. Tanto na análise da legislação quanto na análise dos manuais, esse direcionamento foi observado.

Somando-se a isso estava a incorporação seletiva que os manuais faziam do conteúdo estabelecido pelos programas de ensino: ênfase na aprendizagem preocupando-se em atender às necessidades e interesses da criança, através de um planejamento minucioso das etapas de uma boa aula, da conduta do professor, do passo a passo para manter a disciplina, por exemplo. Os subsídios práticos para a formação de professores estavam ancorados, em sua maior parte, na prescrição de fórmulas prontas que, se levadas com afinco, garantiriam o sucesso da aprendizagem da criança, apesar das reiteradas afirmações em sugestões de "princípios flexíveis".

As ideias renovadas foram implementadas nos termos de sua organização curricular e também em alguns movimentos que daí derivaram: os estágios; a organização das disciplinas em torno da prática que seria firmada nas escolas primárias anexas; a articulação que se fez necessária entre o curso de formação profissional do professor e o curso primário; bem como a comunicação entre professores normalistas e professores primários. Nos termos das prescrições práticas, as ideias ficaram restritas ao excesso de passos formais para a realização das atividades docentes. Não se tratava mais de experimentar os métodos e processos de ensino nas classes primárias, considerando suas 
especificidades para imprimir atitudes, mas sim de transformá-los em normas, não mais em modos de fazer.

Nesse sentido, muitas das concepções da Escola Nova arrefeceram quando passaram do âmbito dos programas para o âmbito das mediações. Sua presença é inegável, bem como a hegemonia dela no campo ideias. Mas por conta da complexidade das estruturas que se intentavam formar, ela perdeu espaço nas opções seletivas de apropriação do currículo pelos manuais pedagógicos. Estes, por sua vez, criaram um discurso escolar sobre o método significando as ações propostas.

\section{Referências}

BRASIL. Decreto-Lei no 8.530, de 2 de janeiro de 1946 - Lei Orgânica do Ensino Normal. Diário Oficial da República Federativa do Brasil, seção 1, p. 116, 4 de janeiro de 1946, Brasília, DF, 1946.

BRASIL. Lei n 4.024, de 20 de dezembro de 1961. Lei de Diretrizes e Bases da Educação Nacional. Diário Oficial da República Federativa do Brasil, seção 1, p. 11429, 27 de dezembro de 1961, Brasília, DF, 1961.

CARVALHO, Marta Maria Chagas de. A escola e a república e outros ensaios. Bragança Paulista: EDUSF, 2003.

CERTEAU, Michel de. A invenção do cotidiano: 1. Artes de Fazer. Petrópolis, RJ: Vozes, 1994.

CHOPPIN, Alain. O historiador e o livro escolar. Revista História da Educação. ASPHE/Fae/UFPel: Pelotas, 2002.

CHOPPIN, Alain. História dos livros e das edições didáticas: sobre o estado da arte. Revista Educação e Pesquisa, São Paulo, v. 30, n. 3, p. 549-566, set./dez., 2004.

ESCOLANO, Augustin Benito. História ilustrada de la escuela en España: dos siglos de perspectiva histórica. Madrid: Fundación Germán Sánchez Ruipérez, 2006. 
LABEGALINI, Andréia Cristina Fregate Baraldi. A formação de professores alfabetizadores nos Institutos de Educação do estado de São Paulo (1933 a 1975). Tese (Doutorado em Educação) - Unesp, Marília, 2005.

MONARCHA, Carlos. Brasil arcaico, escola nova: ciência técnica e utopia nos anos 19201930. São Paulo: Editora UNESP, 2009.

EVANGELISTA, Olinda. A formação universitária do professor: o Instituto de Educação da Universidade de São Paulo (1934-1938). Florianópolis: Editora Cidade Futura, 2002.

ROBALLO, Roberlayne de Oliveira Borges. História da educação e a formação de professoras normalistas: as noções de Afrânio Peixoto e de Theobaldo Miranda Santos. 2007. Dissertação (Mestrado em Educação) - UFPR, Curitiba, 2007.

SANTOS, Theobaldo Miranda. Noções de prática de ensino. São Paulo: Companhia Editora Nacional, $2^{\text {a }}$ edição, 1951.

SANTOS, Theobaldo Miranda. Metodologia do ensino primário. São Paulo, Companhia Editora Nacional, 3 a edição, 1952.

SÃO PAULO. Decreto $\mathbf{n}^{\circ} \mathbf{5 . 8 8 4}$, de 21 de abril de 1933 - Instituí o código de educação do Estado de São Paulo. São Paulo: Imprensa Oficial do Estado de São Paulo, 1933.

SÃO PAULO. SECRETARIA DA EDUCAÇÃO E DA SAÚDE PÚBLICA, DIRECTORIA DO ENSINO. Programmas das Escolas Normaes. São Paulo, 1938. Boletim n. 17.

SÃO PAULO. Decreto $n^{\circ}$ 17.698, de 26 de novembro de 1947: aprova a consolidação mandada elaborar pelo Decreto $n^{\circ} 17.211$, de 13 de maio de 1947. São Paulo: Imprensa Oficial do Estado de São Paulo, 1947.

SÃO PAULO. SECRETARIA DO ESTADO DOS NEGÓCIOS DA EDUCAÇÃO. SERVIÇO DE LEGISLAÇÃO E PUBLICIDADE. Programas das Escolas Normais do Estado De São Paulo. In: COMPÊNDIO de legislação do ensino normal. São Paulo: J. Bignardi \& Cia. Ltda, n. 4, mar. 1953.

SÃO PAULO. DIRETORA GERAL DO DEPARTAMENTO DE EDUCAÇÃO DO ESTADO DE SÃO PAULO. Portaria n. 49, de 2 de dezembro de 1954: Programas das Escolas Normais e Instruções Metodológicas. Diário Oficial do Estado de São Paulo, n. 268, ano 64, 1954.

SÃO PAULO. Programas do Curso Normal. In: COMUNICADO da chefia do ensino secundário e do curso normal. São Paulo: Ed. Do Brasil, n. 18, 3 mar, 1958.

SÃO PAULO. SECRETARIA DE ESTADO DOS NEGÓCIOS DA EDUCAÇÃO. DIVISÃO DE RELAÇÕES PÚBLICAS. Legislação do ensino normal no Estado de São Paulo, atualizada até 30 de abril de 1960. São Paulo, 1960. Publicação avulsa n. 4. 
SAVIANI, Dermeval. História das ideias pedagógicas no Brasil. Campinas: Autores Associados, 2008.

SILVA, Vivian Batista da. História de leituras para professores: um estudo da produção e circulação de saberes especializados nos "manuais pedagógicos" brasileiros (1930-1971). 2001. Dissertação (Mestrado em Educação) - FEUSP, São Paulo, 2001.

SILVA, Vivian Batista da. Saberes em viagem nos manuais pedagógicos: construções da escola em Portugal e no Brasil (1870-1970). 2006. Tese (Doutorado em Educação) - FEUSP, São Paulo, 2006.

VALDEMARIN, Vera Teresa. Os sentidos e a experiência: professores, alunos e métodos de ensino. In: SAVIANI, D.; ALMEIDA, J. S.; SOUZA, R. F.; VALDEMRIN, V. T. O legado educacional do século XX no Brasil. Campinas: SP, Autores Associados, 2006.

VALDEMARIN, Vera Teresa. História dos métodos e materiais de ensino: a escola nova e seus modos de uso. São Paulo: Cortez, 2010.

VIDAL, Diana Gonçalves. 0 exercício disciplinado do olhar: livros, leituras e práticas de formação docente no Instituto de Educação do Distrito Federal (1932-1937). Bragança Paulista: Editora da Universidade São Francisco, 2001. 